\section{'Barrigão à mostra': vicissitudes e valorização do corpo reprodutivo na construção das imagens da gravidez}

\section{"Pregnant belly showing": the vicissitudes and valorization of the reproductive body in the construction of images of pregnancy}

\section{Eliane Portes Vargas}

Pesquisadora do Instituto Oswaldo Cruz (IOC) e coordenadora adjunta do Programa de Pós-graduação em Ensino de Biociências em Saúde do IOC/Fundação Oswaldo Cruz. Instituto Oswaldo Cruz/Laboratório de Educação em Ambiente e Saúde. Av. Brasil, 4365

21045-900 - Rio de Janeiro - RJ - Brasil

epvargas@ioc.fiocruz.br

Recebido para publicação em dezembro de 2009. Aprovado para publicação em setembro de 2010.
VARGAS, Eliane Portes. 'Barrigão à mostra': vicissitudes e valorização do corpo reprodutivo na construção das imagens da gravidez. História, Ciências, Saúde - Manguinhos, Rio de Janeiro, v.19, n.1, jan.-mar. 2012, p.237-258.

\section{Resumo}

Ao analisar as imagens da maternidade e da gravidez procura indicar os valores e as condutas sociais subjacentes a sua criação. Representações do corpo grávido, em circulação na mídia, exprimem, mediante transformações das identidades, uma peculiar combinação de valores que, ao afirmar a liberdade de escolha e de autorrealização, apontam para uma natureza feminina. Concepções científicas acerca da dificuldade de reprodução biológica são amplamente difundidas como problema biológico individual ou do casal. Análises históricas, porém, demonstram que o modo de conceber os eventos reprodutivos transformou-se, indicando como a medicina moderna interveio nos corpos e na família, e como passou-se a afirmar a identidade feminina.

Palavras-chave: transformação das identidades; reprodução; antropologia social.

\section{Abstract}

This analysis of images of maternity and pregnancy seeks to identify the values and social conduct behind their creation. Through transformations of identities, the representations of the pregnant body that circulate in the media reflect a peculiar combination of values which, while affirming freedom of choice and selfrealization, also suggest that a female nature exists. Scientific conceptions of problems related to biological reproduction are widely conveyed as a biological problem attributable to the individual or couple. Historical analyses, however, show that the way we view reproductive events has changed, reflecting how modern medicine has intervened in our bodies and in the family and how female identity has been affirmed.

Keywords: transformation of identities; reproduction; social anthropology. 
$\mathrm{N}$ este artigo $^{1}$ analiso as imagens e representações acerca da dimensão reprodutiva do corpo, tendo em vista as mediações culturais e condutas sociais predominantes na sociedade contemporânea no que concerne às transformações culturais e históricas dos valores relativos à família e à constituição das identidades sociais. A análise limita-se à dimensão simbólica das imagens do corpo e da gravidez como parte da construção moderna da identidade feminina, amplamente difundida nos meios de comunicação. Parto do pressuposto de que a intensa valorização da experiência da gravidez e da maternidade, evidente nas exibições de imagens do corpo a que se assiste atualmente, constitui-se, sobretudo nos estratos médios da sociedade, em um dos ingredientes fundamentais para o desenvolvimento e a popularização das tecnologias de reprodução assistida.

Análises sobre os usos dessas tecnologias apontam para um grande interesse de diversos setores da sociedade. $\mathrm{O}$ tema se populariza associado à medicina e à mídia, que informam aos potenciais usuários dos serviços médicos - homens e mulheres dispostos a ter o 'próprio filho' - sobre experiências bem-sucedidas de reprodução assistida. Portanto o incremento, consumo e popularização das tecnologias médicas reprodutivas encontram-se no cerne desse moderno modo de realizar o desejo de ter filhos entre indivíduos e/ou casais comprometidos com o projeto de reprodução biológica (Ramírez-Gálvez, 2003; Luna, 2003; Tamanini, 2009). Cabe destacar que a infertilidade e suas representações, tratadas aqui tangencialmente, servem de contraponto ao destaque dado na mídia à gravidez e à maternidade como parte da identidade feminina. O que pretendo assinalar são os indícios de uma acentuada valorização da maternidade assentada na experiência corporal da gravidez, fartamente explorada pelos meios de comunicação, e sua coexistência com uma gama de abundantes informações e imagens sobre o tema da reprodução humana, que relacionam os avanços científicos à solução para os problemas de infertilidade.

O grande número de programas de televisão que apresentam diversos temas de base científica faz com que seja possível perceber o privilégio concedido ao corpo biológico - e portanto às noções essencialistas - nesse tipo de comunicação, no qual a explicação do amor materno revela uma lógica de diferenças relativas ao gênero (Ribeiro, Rohden, 2009). A forte presença das ciências biológicas na divulgação do conhecimento científico sobre assuntos relacionados à reprodução e à sexualidade na mídia foi considerada por Citeli (2002) fator relevante na rede de produção da ciência brasileira. Isso permite compreender os pressupostos que embasam a construção de poderosas imagens acerca das técnicas a serviço da reprodução, bem como a popularização dos novos procedimentos da biotecnologia (Luna, 2007). Encontra-se também em circulação na mídia uma representação negativa da mulher sem filhos, que representa o revés da valorização da reprodução ligada à identidade feminina.

Mediante o exposto, o artigo discute os nexos entre a exposição midiática do corpo grávido e as representações predominantes sobre corpo e reprodução que expressam as articulações entre natureza e cultura. Ao evocar a figura do par conjugal heterossexual como parte desse conjunto de representações, a mídia expõe a seu modo um dos aspectos mais relevantes do consumo das tecnologias reprodutivas: a centralidade da reprodução biológica como via de constituição de família. 
Estas reflexões beneficiam-se da análise da configuração do desejo por filhos no âmbito conjugal desenvolvida em um estudo etnográfico amplo sobre 'casais inférteis' (2002-2006). Nesse foram analisadas trajetórias individuais e de casais de estratos médios no estado do Rio de Janeiro, a partir das quais focalizei as dificuldades apontadas pelos casais, em seus próprios termos, para ter filhos biológicos, e suas reverberações na relação conjugal e familiar (Vargas, Russo, Heilborn, 2010). Além da observação do contexto de interação dos casais e das entrevistas realizadas ${ }^{2}$, o corpus etnográfico reuniu extenso material sobre o tema, levantado na internet e na mídia em geral, incluindo edições da revista Caras (2004-2006), objeto da presente análise. Em 28 edições de Caras (números 587 a 606), entre janeiro e julho de 2005, foram levantados todos os registros fotográficos de matérias posteriormente agrupadas em três conjuntos: gravidez, maternidade e casamento. No presente artigo são considerados os dois primeiros grupos, e as informações sobre o perfil da revista foram atualizadas.

Caras, uma publicação da Editora Abril, representa uma modalidade de revista de entretenimento de circulação semanal nacional e é considerada por seus produtores um dos maiores sucessos do atual mercado editorial do gênero. De acordo com dados da literatura (Mira, 2001), o que caracteriza uma revista popular é sua circulação entre diferentes perfis econômicos. Os assuntos abordados, como os últimos acontecimentos do mundo das celebridades do Brasil e do exterior e a fofoca em geral, são os principais apelos dessa modalidade de publicação, sendo considerados elementos essenciais para a manutenção da circulação. Levando-se em conta variáveis como gênero e classe socioeconômica do leitor na análise do processo de segmentação das revistas (Mira, 2001), Caras apresenta especificidades voltadas para públicos diversificados. Destaca-se, por exemplo, como uma revista dita 'de fofoca', característica considerada típica não só de um público feminino, mas também das classes populares. O uso da linguagem fotojornalística também a aproxima das publicações tipicamente voltadas para os estratos economicamente inferiores.

Embora requeira o dispêndio de dinheiro supérfluo, ou seja, aquele não destinado ao provimento das condições básicas de existência - o que em geral é possível apenas para as classes mais favorecidas economicamente -, a revista Caras tem ampla circulação por figurar em espaços nos quais transita muito público, como salões de beleza e consultórios médicos, nos quais, de modo geral, a leitura faz parte de uma interação costumeira entre mulheres de diferentes estratos sociais. Considerando o preconceito que envolve as revistas denominadas de fofoca, as mulheres de nível superior e de maior capital cultural utilizam algumas estratégias para ter acesso à revista, tais como dizer que vão 'dar uma olhada', pois na sua percepção trata-se de uma literatura de pouco prestígio ou de interesse popular (Mira, 2001). Uma combinação de elementos desse tipo favorece a leitura de Caras nos estratos da sociedade de maior poder aquisitivo, considerando-se ainda a prática comum de circulação de algumas revistas entre os diferentes estratos da população. Além disso, essas mídias se apresentam cada vez mais como produtos intercambiáveis, as matérias impressas circulam também na televisão, sobretudo nos canais abertos acessados de forma mais ampla pelo conjunto da população.

Foram destacados alguns aspectos característicos da circulação desse tipo de revista com o intuito de chamar a atenção para os recursos acionados na comunicação, uma vez que 
eles colocam em cena determinadas configurações simbólicas modeladoras da experiência reprodutiva de grande significado quanto aos valores sociais que predominam em nossa sociedade. Trata-se de pensar o ato comunicativo, para além de dispositivos e suportes específicos (aí incluídas imagens, textos etc.), como uma instância de produção de sentidos que "exprime sempre uma pulsação da vida social" (França, 1995, p.65). Procuro, portanto, explorar nas imagens de Caras as construções do corpo em sua dimensão reprodutiva, e as aproximações e distanciamentos dessa construção em relação ao conjunto de práticas variáveis em torno do tema quanto a seus aspectos históricos e culturais a partir dos anos 1960, como veremos posteriormente.

Um dos aspectos motivadores da análise realizada foi o abundante material oferecido pela revista que, quando reunido, oferta-nos uma oportunidade de observação mais acurada das representações do corpo e dos estereótipos construídos em torno da experiência da maternidade. Trata-se de um tema já analisado, mas revisitado em função das inovações no campo biomédico, especialmente no que tange às tecnologias reprodutivas (Luna, 2002). Representações acerca da gravidez materializadas nas glamorosas imagens veiculadas pela revista expressam uma valorização da maternidade como essência da identidade feminina, sendo o exercício da reprodução retratado como um domínio autônomo, ou seja, desvinculado das relações sociais que o determinam.

A despeito das restrições a serem feitas a esse produto midiático, a partir de uma leitura crítica, o material alcança seus leitores e é considerado um empreendimento bem-sucedido em termos comerciais. Sob a perspectiva da produção, em 2009 a revista teve o total de 4.114.327 leitores, em sua maioria mulheres, solteiras e das classes sociais superiores: dos leitores, $75 \%$ eram mulheres, $51 \%$ solteiros, $64 \%$ com idade entre 20 e 49 anos, e $64 \%$ pertencentes aos estratos economicamente superiores, segundo informações da revista. De acordo com relatório da Editora Abril (2001), dados do Instituto de Verificação de Circulação de Revistas do mercado brasileiro informam que Caras ocupou em 2000 o décimo lugar das revistas mais vendidas no Brasil por volume médio.

A revista informa que $94 \%$ dos leitores moram com a família e, reiterando esse dado, anuncia que "os leitores de Caras gostam de estar com a família" (Revista Caras, 2008). Em cinco edições especiais anunciadas pela revista é possível identificar dois temas correlatos: um apresenta o "Anuário Noivas" e outro, o "Anuário do Bebê". De oito datas especiais anunciadas encontramos cinco relacionadas à maternidade e ao casamento, em que prevalecem imagens de casais e família: "Dia da Mulher", "Dia das mães", "Dia dos Namorados", "Dia dos Pais" e "Dia das Crianças". Foram também incorporadas à pesquisa informações oriundas de diversos canais da mídia (impressa e televisiva), uma vez que os produtos culturais veiculados nesses meios são cada vez mais intercambiáveis. Soma-se a esse aspecto a proximidade de Caras com o universo sociocultural dos casais 'inférteis' de camadas médias - no qual se inserem os casais da pesquisa. Isso os torna consumidores em potencial não só da revista mas sobretudo de recursos e tecnologias médicas utilizados com o objetivo de realizar o 'sonho de ter filhos', expresso sobretudo pelas mulheres.

Este texto está organizado em três partes: a primeira identifica de que forma as conexões entre sexualidade e reprodução estão presentes nos discursos sociais predominantes sobre a maternidade e em que medida, ao afirmar a maternidade como uma construção de si e 
uma autorrealização baseada na liberdade de escolha, apontam para uma natureza feminina. Procuro indicar como essa combinação de valores acerca da maternidade na sociedade contemporânea, relacionada às transformações identitárias históricas e sociais, é veiculada na mídia, nas imagens do corpo reprodutivo. A segunda parte aponta para dimensão reprodutiva do corpo como espetáculo midiático, tomando como exemplo as edições de Caras, bem como os ideais de feminino e de maternidade retratados nas suas edições. A terceira apresenta brevemente as representações depreciativas da mulher infértil também presentes em alguns produtos da mídia, como um revés da valorização da reprodução, em um contexto social no qual parecem prevalecer a liberdade de escolha e opção nas práticas reprodutivas - incluindo a opção de ter ou não filhos - e nas questões de trato íntimo.

Busco identificar, em imagens atuais, indícios de mudanças no modo de conceber os eventos reprodutivos vis-à-vis as transformações socioculturais e o processo histórico mais amplo, que teve lugar a partir dos anos 1960, e que se vêm contrapor a uma visão negativa do corpo feminino alicerçada em uma tradição médica. A crítica a essa visão resulta na afirmação de uma identidade feminina, que concorre com a ideia de recusa da maternidade como essência e, portanto, como um dado 'biológico', integrando, por sua vez, o debate sobre as relações entre natureza e cultura.

\section{Atuais evidências da valorização do corpo na mídia: uma peculiar combinação de valores}

Como já assinalado, observa-se uma peculiar valorização da maternidade nos modos como o corpo grávido tem sido representado, 'exposto' e 'exibido' nos meios de comunicação. Nas últimas décadas, a mídia brasileira e internacional promoveu uma ampla exposição pública do corpo grávido, enfatizando a imagem de mulheres que optam pelo exercício da maternidade de forma muito significativa, uma vez que tais imagens, tanto da gravidez quanto da maternidade, contêm elementos de afirmação de liberdade de escolha e de autorrealização.

As antigas revistas femininas nacionais, denominadas revistas da 'mulher brasileira', diversificaram-se ao longo do tempo de acordo com o gosto do público (Mira, 2001). Destaco algumas de suas características, sem pretender esgotá-las, ciente da existência de análises já consolidadas sobre esse tema em variadas perspectivas. No vasto e diversificado mercado editorial de revistas, surgiram aquelas dedicadas aos cuidados com a gravidez e a saúde (Shari, Faye, 2004), que por vezes apresentam uma visão autônoma da gestante, representada em relativo isolamento de seu círculo social, salvo pela estreita relação com os especialistas médicos (Rezende, 2011). Com relação à participação de profissionais da área médica e afins, especializados em crianças e no relacionamento com a mãe, alguns autores chamam atenção para a produção de literatura especializada na educação dos filhos, desde os cuidados com o recém-nascido até a adolescência (Martins, 2008), que contribuiria para a construção de um ideário de maternidade apoiado no conhecimento científico, incluindo a participação ativa das mulheres, como analisado por Freire (2008) para a década de 1920. Swain (2001) vislumbra, por sua vez, a presença nas revistas destinadas ao público feminino, em geral, de assuntos circunscritos à esfera íntima - sedução e sexo, família, casamento, 
maternidade e futilidades - ficando ausentes outros temas como, por exemplo, os relativos ao debate político e a assuntos econômico-financeiros. Para a autora, o feminino fica reduzido a uma equação simples: as mulheres seriam vistas como consumidoras, como parte do funcionamento dos setores industriais ligados às suas características 'naturais' tais como domesticidade (eletrodomésticos, produtos de limpeza, móveis), sedução (moda, cosméticos, o mercado do sexo, do romance, do amor) e reprodução (produtos para maternidade/crianças em todos os registros, da vestimenta/alimentação aos brinquedos) (Swain, 2001, p.4). Enfim, as atuais revistas voltadas ao público feminino parecem conter certas características já presentes em produções mais antigas, como apontado pelas análises, mas que são revisitadas com vistas a alimentar o interesse de seu público receptor, conforme o idealizam.

Tratando-se de Caras, não se pode falar em intenção pedagógica no ensinamento de cuidados com a saúde ou outro tipo de conteúdo dirigido ao público feminino. Trata-se, segundo seus idealizadores, de uma revista de entretenimento interessada na diversão e no lazer de seus leitores ou, em seus próprios termos, uma publicação que atende a leitores que buscam um estilo de vida positivo e conhecer os últimos acontecimentos de um mundo real e de sonhos. Chama atenção, por exemplo, o destaque conferido à vida privada de casais famosos e a glamorização envolvendo as estrelas da TV, projetadas como modelos bem-sucedidos de mãe, de mulher e de profissional, modelo idealizado, a ser copiado e invejado (Machado, Hagen, 2004). São imagens que, apesar de balizadas por tipos ideais, contribuem para uma identificação 'prestigiosa' (Mauss, 1974) do público leitor com modelos a serem seguidos, facilitada pela impressão de proximidade dos astros de TV e do cinema e pelos aspectos positivos da vida de seus personagens exibidos.

Portanto, aspectos ligados à vida familiar mais comum, relacionados sobretudo a valores e atitudes, parecem deixar suas marcas. Pode parecer um truísmo apontar o uso dos astros na mídia e a exposição da intimidade dos mesmos, pois a rigor não traz nenhuma novidade. No entanto, isso expõe a robustez de um determinado tipo de representação de ideal feminino ainda em vigor que, quando revisitado, aponta para um horizonte nem sempre alcançado, na maioria das vezes muito distante do campo de possibilidades das mulheres de diferentes classes sociais.

As representações da gravidez na mídia em geral revelam o 'barrigão à mostra' de atrizes da TV nacional e internacional, e do cinema. Vestes, esportivas ou sociais, não deixam dúvidas quanto à existência da gravidez. Ao contrário das batas típicas dos anos 1950, as roupas usadas atualmente são justas e deixam proeminente a barriga. A imagem da mulher grávida contemporânea, mesmo com o corpo recoberto, evidencia a barriga. Uma característica marcante de tais imagens são as mãos no ventre, um clássico desse tipo de representação (Borin, 1991). As artes pictóricas do século VI já enunciavam o poder que reside na fecundidade e no ventre feminino, retratado pela mulher grávida que apoia sua mão sobre o abdômen. Nas representações da Antiguidade, a mulher, ciosa dessa condição, mantém o olhar intenso do espectador, indicando o mistério evocado pelo ventre feminino, como se observa em La donna gravida, de Raffaello Sanzio (1505-1506), na Galeria Palatina, em Florença. Nas representações contemporâneas, das quais Caras constitui um exemplo, outro personagem, o pai, também apoia a mão sobre o ventre da mulher. Nesse novo 
cenário, observa-se mais um processo contemporâneo: a promoção do feto ao estatuto de criança, com qualidades concretas, no decurso da gestação, conforme analisado por Lo Bianco (1985) e Chazan (2008). De acordo com a primeira autora, esse processo permite uma reconstrução da maternidade, cujo exercício comporta representações muitas vezes contrastantes entre si, afastando-se de imagens idealizadas. Pai e mãe são geralmente fotografados sorridentes, 'exibindo a barriga'; o casal contemporâneo de 'grávidos' (Salem, 1989) posa nas imagens para uma fotógrafa 'especialista em gestantes', cuja especialização constitui uma novidade no mercado. Esse registro fotográfico diferencia-se sobremaneira das fotos de estúdio do início do século que retratavam o universo familiar, como indicou Leite (2000). Como os 'retratos de família' daquele momento, analisados pela autora, a prática de fotografar gestantes da forma como é feita atualmente aponta um lugar ocupado pelo corpo feminino na cena social, cuja centralidade imagética o representa de modo autônomo e apartado das relações sociais que o constituem.

Imagens do corpo descontextualizadas foram também analisadas por autores como Novaes e Salem (1995) no estudo do embrião. Nesse trabalho, as autoras evidenciam a construção de imagens do feto, presentes em revistas de divulgação sobre o tema, separadas do corpo da mulher, ou seja, como seres autônomos e desvinculados do contexto no qual se inserem. No caso específico da fertilização in vitro, tais imagens conectam-se às representações da produção extracorporal do embrião que, segundo as autoras, apresentamse desvinculadas da teia de relações sociais, o que consiste em uma 'ilusão', como propõe Louis Dumont, ou seja, uma distorção (Salem, 1997). No caso do material aqui descrito, as imagens da gravidez centram-se no corpo da grávida e do casal individualizado, autônomos no que diz respeito ao contexto das relações familiares, ainda que tal autonomia seja relativa, como bem o demonstraram os casais entrevistados na pesquisa mais ampla sobre 'casais inférteis'. No entanto, tal representação reflete, por sua vez, as mudanças culturais e sociais mais amplas que ocorreram a partir do início do século XX, e que são apresentadas com características de espetáculo visual nos meios de comunicação.

A exposição pública dos corpos, sobretudo do corpo grávido, é recente. O fenômeno da gravidez como 'espetáculo' exprime-se nos ensaios fotográficos dos anos 1980. A divulgação dos corpos grávidos seminus aponta uma clara referência à sexualidade e à erotização do corpo de personagens como Leila Diniz, Luiza Brunet e Wanderléa, para citar somente alguns. O nu erótico do corpo grávido como manchete das capas de revista atesta as transformações dos valores a partir dos anos 1960, pois vem substituir as imagens infantilizadas das mulheres grávidas, dos anos 1950, quando prevaleciam as batas largas e os vestidos pregueados que compunham a indumentária da mulher gestante (Belmiro, 1992).

Na virada do século XIX e primeira metade do século XX, a prática de exibição dos corpos de mulheres grávidas, em regra, não existia. Entre os anos 1930 e 1950, as imagens da gravidez eram escassas e talvez restritas a iniciativas individuais. A significativa carência de registro nesse período sugere a pouca expressividade desse tema como interesse fotográfico e de consumo cultural. Não se exclui, no entanto, a possibilidade de sua existência nos acervos pessoais, de forma periférica. Belmiro (1992) informa que o modelo da gestante e mãe, nessas décadas, especialmente nos anos 1950, pouco difere daqueles produzidos pelos 
discursos disciplinadores de meados do século XIX e início do seguinte. As estratégias disciplinadoras traduzem-se na aproximação da representação da gravidez ao universo infantil, o que promove uma indiferenciação da mulher no que concerne à sua individualidade, pela correlação direta de sua imagem com o mundo da casa e da família. Nos anos 1950, a disciplina do corpo impingia um silenciamento dos aspectos ligados à intimidade, impossibilitando uma divulgação dos eventos sexuais e reprodutivos tidos como pertencentes a essa esfera.

De fato, se tomarmos como referência o repertório da moda feminina dos anos 1920 ao início da década de 1950 veremos uma transformação paulatina na exposição do corpo feminino e da intimidade, relacionada aos estilos de vida. A participação, no Brasil, das mulheres na Segunda Guerra Mundial, entre 1939 e 1944, é o contexto em que o vestuário feminino sofre alterações, com o uso de roupas mais práticas, leves, com menos volume e mais curtas. Isso se dá por razões culturais e práticas, decorrentes das transformações culturais no plano dos valores, atitudes e comportamentos, mas também por restrições econômicas e pela convocação das mulheres para trabalhos voluntários, antes exercidos exclusivamente por homens (Simili, 2008). Determinadas versões posteriores de feminilidade deixariam o corpo gradativamente à mostra, como se vê no caso dos 'tornozelos à vista' que, de forma inaugural, antecipa as alterações, por exemplo, do comprimento das saias, que concentravam as atenções nos anos 1920 . O vestuário da mulher gestante daquele período distanciase igualmente da atual 'moda gestante', que associa maternidade e feminilidade aos denominados estilos de vida da mulher moderna. Ao contrário das cinturas marcadas de hoje, prevaleciam roupas soltas no corpo, o suficiente para encobrir os contornos da gravidez, sendo as 'batas' largas e as golas 'bebê' sua melhor expressão, como demonstrou Belmiro (1992). No entanto, a progressiva exposição do corpo já neste período deixa entrever as transformações que ocorreriam nos anos 1960, como veremos a seguir.

Os usos físicos do corpo relacionam-se a um conjunto de sistemas simbólicos indissociável dos sentidos e dos valores a ele atribuídos; portanto, não se trata de analisá-lo como suporte de identidades sociais ou como objeto cultural que reproduz, servindo como base epistemológica, os dualismos corpo/espírito e natureza/cultura, conforme apontado por Maluf (2002). Tratando-se da dimensão reprodutiva em seus aspectos simbólicos, os usos das imagens do corpo nos meios de comunicação em geral, retratado em cenas públicas e privadas, indicam as imbricações entre sexualidade e reprodução. Nas formas atuais de expressão, os sentidos da maternidade apontam para uma intensa exaltação da experiência corporal da gravidez como um valor ligado à identidade feminina, sobretudo heterossexual, entre os estratos médios letrados da sociedade e também nos grupos populares, ainda que de modo diferenciado.

No Brasil, os níveis de fecundidade entre os diferentes estratos sociais não são homogêneos, de acordo com dados demográficos (Berquó, Cavenaghi, 2004). Isso coloca o Brasil, juntamente com países latinos como o México e a Colômbia, em patamares demográficos diversos de outros países, que apresentam uma distância menor entre os vários grupos socioeconômicos. Para a maior parte da população brasileira os níveis de fecundidade são baixos. Mas ainda existem grupos - e representam uma parcela cada vez menor da população - que se mantêm em patamares médios, como no início da transição demográfica, em 
meados da década de 1960. A educação e a renda são fatores relacionados ao nível de fecundidade. Geração e classe social fazem diferença na interpretação dos dados de fertilidade entre os grupos da população quando se trata de gravidez entre jovens ou mulheres pobres.

A relação de causalidade presente na mídia entre fertilidade e pobreza baseia-se em uma exigência de regulação da fertilidade entre grupos populares presente na realidade brasileira. Esse raciocínio reducionista e persistente muitas vezes desemboca na relação criminalidade/ pobreza (Heilborn, 7 out. 2004) a despeito dos resultados de pesquisa que informam que, ao contrário, o perfil demográfico brasileiro está próximo ao dos países europeus (Berquó, Cavenaghi, 2004). As análises demográficas sugerem, portanto, que mudanças nas práticas reprodutivas estão em curso, mas se torna necessário analisá-las em relação a contextos específicos.

O valor positivo do corpo feminino na experiência da reprodução, a partir dos anos 1960, vem contrapor-se a uma tradição médica ocidental alicerçada em uma visão negativa do corpo das mulheres, que tem como representante proeminente em períodos históricos anteriores ao atual a obstetrícia. Sobre esse aspecto Rohden (2002) identifica que o surgimento da ginecologia como especialidade médica no século XIX acabou por atrelá-la à função procriadora uma vez em que se apropriou das descobertas na área da obstetrícia, ainda que a ultrapassasse. A construção de parâmetros para uma medicina da mulher deuse a partir do discurso da diferenciação em torno dos sexos - características da natureza atribuídas a homens e mulheres - que, de acordo com Vaitsman (1994), transformou a sexualidade e o amor entre eles em normas de saúde.

De acordo com essa perspectiva, o discurso científico, jurídico e popular a respeito das características próprias de cada sexo tornou-se dominante e encontra-se intimamente relacionado às transformações sociais do período. A valorização do papel da mulher na sociedade, já no início do século XX, ressaltou sua importância para a nação, a partir de certa reordenação no discurso médico que se refletiu em maior aproximação entre a medicina e o Estado. Em paralelo com essa tendência desenvolveram-se ideias ligadas à eugenia, à difusão dos métodos contraceptivos, à inserção do trabalho feminino na esfera pública, à reivindicação de direitos por grupos de mulheres e à relevância das questões relativas à população e à raça. Ressalvando-se as diferenças do contexto histórico e cultural, a centralidade da reprodução para o modelo de intervenção biomédico como conhecemos hoje, no que diz respeito aos debates e pesquisas em torno de temas como concepção e contracepção, amamentação, gestação e parto, não é nova, mas assumiu novos contornos.

A medicalização da gravidez e do parto passou a ser revista, por sua vez, no final dos anos 1960, a partir de um espectro mais amplo de críticas à medicalização da saúde, correlacionadas a diversas manifestações culturais e a um universo moral identificado com o chamado movimento de 'contracultura'. Esse movimento caracteriza-se para Heilborn (2004) como um marco sincrético de uma série de modulações da cultura contemporânea que integra a experiência dos sujeitos. Russo e Ponciano (2002) e Salem (1991) o concebem como um movimento cultural, expresso em diversas manifestações culturais da juventude e nos saberes eruditos, de forte reação antirracionalista, que floresce na segunda metade do século XX. As autoras consideram que esses desenvolvimentos, incompatíveis à primeira 
vista, ocorreram simultaneamente: o movimento de contracultura como reação ao racionalismo e a ênfase biologizante na compreensão dos fenômenos humanos.

Diversas manifestações culturais afinadas com a ideologia dos anos 1960 expressam um universo específico de valores, entre os quais um engrandecimento da 'natureza' e a exaltação da expressão das liberdades individuais. Trata-se, segundo Rojas (2004) de um progresso radical na célula familiar em direção a novas formas de organização familiar, desencadeado pelo espraiamento do feminismo e da antipsiquiatria. Para as mulheres, as atenções se voltam ao exercício da sexualidade com prazer e à recusa de partos considerados 'artificiais', via tecnologia médica, priorizando um maior conhecimento e uso da 'fisiologia do parto'. Seja na esfera da sexualidade ou da maternidade, especificamente com relação à parturição, a crítica à medicalização tem por base uma reivindicação no plano dos direitos de maior autonomia e controle das mulheres sobre seu próprio corpo. Alguns movimentos, como o movimento pela 'humanização do parto' e pela 'morte natural' (Tornquist, 2002; Menezes, 2003) exemplificam essa tendência, pois privilegiam a totalidade físico-moral da experiência humana em detrimento das concepções mecanicistas e dicotômicas vigentes entre corpo e mente. Entre os ideais contemporâneos de nascimento e de morte encontra-se uma íntima relação com a ideia de natureza, sugerindo que o 'tom moral' característico do imaginário dos anos 1960 ainda se faz presente Salem (1991). Algumas tendências demográficas indicam o alcance dessas transformações, que atingem as relações familiares e de gênero, bem como o exercício da sexualidade e das práticas reprodutivas.

A importante redução das taxas gerais de fecundidade observada a partir da virada do século XX é consequência, entre outras razões, da grande difusão e do maior acesso a recursos contraceptivos e abortivos, e da entrada das mulheres no mercado de trabalho a partir dos anos 1960. Esses fatores combinados contribuíram para a redução do tamanho das famílias, o que não significa uma reversão na valorização do desejo de ter filhos, mas sua manutenção remodelada pelos novos ideais de maternidade e paternidade em curso. A contracepção - e sua bem-sucedida disseminação pelas políticas de controle e adesão por parte das mulheres - emergiu como um elemento que interfere na relação conjugal e favorece a configuração de uma demanda por filhos como fruto da escolha do casal e do indivíduo. Sobretudo entre os estratos médios letrados, o uso de recursos contraceptivos é balizado por questões relativas às trajetórias de vida, aos projetos profissionais, à dinâmica conjugal e à relação familiar, que resultam em uma decisão racional e na possibilidade de escolher livremente o melhor momento para ter filhos. Assim, a valorização da maternidade nos termos que conhecemos hoje encontra-se amparada pelo ideário moderno de liberdade e autonomia, que permeia várias esferas do social, sendo a intimidade, e as decisões reprodutivas que dela fazem parte, um lugar de escolhas no qual prevalece a negociação entre os parceiros.

No Brasil, a transição da fecundidade ocorreu entre 1965 e 1995 (Bozon, 2004). Segundo Bozon (2004) dados do Instituto Brasileiro de Geografia e Estatística do período de 1991 a 2002 informam uma queda no número de casamentos (considerando-se apenas as uniões legais), um aumento das dissoluções dos casamentos (incluídos as separações judiciais e os divórcios), um aumento de famílias chefiadas por mulheres e maiores percentuais de homens vivendo sós. Esse conjunto de informações revela a variabilidade dos arranjos e associações 
entre indivíduos (mulheres ou homens) que resultam em relação conjugal (implicando ou não coabitação) com geração de filhos (biológicos), com criação de filhos (adoção) ou sem filhos. Há ainda os indivíduos que não se associam e têm filhos, e os que não se associam e não têm filhos. Na interseção dessas combinações, aqueles com orientação homossexual expressam novas modalidades de associação conjugal e exercício de maternidade e paternidade (Uziel, 2007; Tarnovski, 2004; Knibiehler, 2001).

A partir da década de 1980 alguns estudos focalizados na maternidade e no desejo de filhos ressaltam a forte presença de um discurso normativo da maternidade que persiste em paralelo ao discurso atual da 'opção' de ter filhos, tanto nas camadas médias quanto populares. Mas novos arranjos familiares centrados nos filhos denotam novos modelos de família (Sorj, Goldemberg, 1999). Deve-se ter em conta que outros elementos estão em jogo. As recomposições familiares e a mobilidade social intergeracional são fatores que contribuem para uma maior individualização dos sujeitos e das relações familiares, sendo a parentela, que muitas vezes exerce pressão sobre os casais para que se reproduzam e as transmissões entre as gerações - materiais, afetivas e apoios diversos - alguns elementos de base da reprodução familiar (Peixoto, De Singly, Cicchelli, 2000). Portanto, ainda que não reproduzir seja uma decisão factível no horizonte de possibilidades dos indivíduos, a opção de ter filhos parece prevalecer em relação a não tê-los (Berquó, Cavenaghi, 2004), bem o demonstram os casais analisados na pesquisa e classificados medicamente como inférteis.

Retornando a um cenário anterior, podemos observar nas últimas décadas do século XX uma intensificação dos registros fotográficos da maternidade e da gravidez na mídia em diversos formatos e canais. Na década de 1990, houve grande repercussão internacional com a divulgação da foto da atriz americana Demi Moore, grávida e nua, estampada na capa da revista Vanity Fair (Lois, Aug. 1991). Segundo Belmiro (1992), nessa mesma década no Brasil a revista Manchete - semanário popular de entretenimento e informações diversas - divulgou em matéria intitulada "O bebê de proveta de Monique Evans", a concepção com o auxílio de tecnologia reprodutiva. O corpo nu grávido central na foto de capa, extraída do material de Belmiro (1992), apresenta-se, desta vez, como componente de um casal, uma categoria fundamental naturalizada pelo discurso médico na problematização da infertilidade (Tamanini, 2009).

\section{A dimensão reprodutiva do corpo como espetáculo e os ideais de feminino e maternidade: 0 exemplo de Caras}

Como dito anteriormente, a análise dos registros fotográficos das edições de Caras resultou na classificação de três conjuntos de imagens: imagens da gravidez, da maternidade e do casamento e aqui serão contemplados especialmente os dois primeiros grupos. Não obstante, parece-me apropriado considerar no conjunto levantado as estreitas relações entre as representações de gravidez e maternidade e os ideais de família e vida conjugal. Merece atenção, por exemplo, o destaque conferido às cenas de casamento, que remetem a valores relativos à constituição da família e ao desejo por filhos, o que indica, em detrimento das variações de arranjos observados no contexto das atuais práticas sociais, a permanência de um modelo de casamento, sobretudo como ritual e ideal a ser alcançado. Hollenbach 
(2003) reforça essa compreensão ao não identificar em nenhuma das matérias analisadas na revista TPM referências à possibilidade de a mulher ser feliz sem um companheiro, o que reforça a ideia de o casamento ser retratado no senso comum como um modelo a ser seguido e, por isso, fundamental à vida de qualquer pessoa. Essa revista foi criada como alternativa às revistas femininas consideradas mais tradicionais, em uma tentativa de ultrapassar os antigos ideais de uniões. No entanto, segundo a autora, o rompimento com modelos de com-portamento considerados mais tradicionais parece não significar uma negação da impor-tância do casamento como valor social.

Gonçalves (2007), por sua vez, reconhece nos discursos acerca das mulheres 'sós' publicados na mídia escrita - jornais e revistas de circulação local e nacional - uma tendência à reafirmação das oposições normativas relativas ao gênero. Não só o casamento, mas o par conjugal, reiteradamente representado nos meios, tem como referência e modelo social predominante a família conjugal, modelo que persiste como matriz para a realização do desejo de filhos, como parte da vida a dois, como se pode observar na pesquisa sobre casais de camadas médias, inférteis biomedicamente. Nesse contexto de muitas variações relativas às práticas e ao relacionamento conjugal que afirma sobretudo o 'viver a dois' como opção, o valor atribuído ao 'casal' com filhos amplifica-se.

Nessa circunstância, em que a liberdade de opção encontra seus limites na biologia, os indivíduos exprimem não só a importância simbólica do filho como uma realização individual, mas sua extrema relevância para a constituição do casal. A não reprodução involuntária provoca a expressão do desejo de filhos de forma exacerbada. Reproduzir não é mais visto como conseqüência natural do casamento, mas como fruto de uma racionalização encarnada na ideia de 'projeto' que se traduz em uma decisão, seja do casal ou do indivíduo. A presença do desejo de filhos combinada com a ausência de gestação resulta na 'infertilidade' como um evento biomédico. Desse modo a infertilidade é mais ampla que a pura ausência de gravidez como definida pelo discurso biomédico. Parto do pressuposto de que a reprodução - e também a não reprodução - representa hoje uma opção para homens e mulheres, por sua dissociação da sexualidade. No entanto, a não reprodução, quando involuntária, coloca em evidência de forma permanente o desejo de constituição de família, e nem o fato de as mulheres terem alto grau de escolarização, como no caso na pesquisa dos casais com infertilidade, é suficiente para colocar em xeque esse aspecto da identidade feminina que é ter filhos.

No material analisado extraído de Caras, dois modos de expressão são complementares: um primeiro que liga o corpo feminino às campanhas publicitárias e um segundo que veicula as imagens da gravidez e da maternidade de personalidades famosas e midiáticas. No que concerne às reportagens dedicadas ao Dia das Mães, o corpo reprodutivo associase aos bens e serviços e ao consumo financeiro. Entre os diferentes tipos de campanha publicitária, destacam-se as imagens da maternidade centrada na mulher grávida ou, como denominado nesse tipo de anúncio, na 'futura mamãe'. O número especial de Caras, dedicado às mães, publicado em maio de 2005, divulgou duas matérias comerciais significativas. Na primeira delas, a mão repousa sobre o ventre em formato de coração, e a mensagem é bastante sugestiva: "Uma mensagem a todas as mães. Principalmente: àquelas que não veem a hora de trocar fraldas logo" (grifo meu). Na segunda a mulher grávida é 
retratada tendo, ao fundo, um visual de mar e montanha cravado em um centro urbano bastante conhecido, a enseada de Botafogo, no Rio de Janeiro. Mais que uma cena estática, o fundo de natureza sobre o qual é retratada a imagem do corpo feminino é, a um só tempo, parte e todo no universo dessa representação. O mar, a montanha e os corpos se complementam. O fundo representado pela natureza é parte da roupa da mulher, que apenas parcialmente recobre o ventre e é, ao mesmo tempo, o todo, que emoldura o cenário. A mulher da foto, por sua vez, mistura-se à paisagem e dela se serve para a exposição do ventre, no qual seu olhar repousa fixo. A mensagem transmitida, nesse caso, é igualmente sugestiva: 'Você é o que você sente'. Estas representações convergem no sentido de enfatizar o corpo grávido como lugar de expressão dos significados da maternidade, tanto pela indistinção entre mulher e natureza, como também por circunscrever a maternidade à experiência do sensível que se liga à construção de si.

Para além dos dias comemorativos, como as edições especiais do Dia das Mães, as imagens da gravidez e da maternidade exprimem-se pela exposição das personalidades famosas. Nesse caso, elas expressam ainda melhor o quanto a maternidade e a gravidez encontramse valorizadas atualmente no universo das camadas médias.

Em Caras, as imagens sobre a gravidez revelam o 'barrigão à mostra' com uma característica marcante, a imagem das mãos no ventre, já anteriormente indicada, um clássico nesse tipo de representação que enuncia o poder da fecundidade na sociedade antiga (Perrot, Duby, 1991). Além das vestes que, por serem justas, ao contrário das mencionadas batas dos anos 1950, não deixam dúvidas quanto à presença da barriga, outra característica marcante pode ser observada: a presença do pai, apoiando a mão e abraçando o ventre, marca sua participação na cena.

Também encontra-se presente nessas imagens uma concepção de maternidade que se concretiza ainda no decorrer da gestação e que promove a transformação da percepção do feto, que passa a ser considerado uma criança. As referências antecipadas à gestante como mãe podem ser vistas na alusão a essa figura ainda no percurso da gestação. Quanto ao feto, ascende ao estatuto de criança ainda no decurso da gestação, como pode ser observado nas chamadas de abertura das matérias: "Nem nasceu e já virou destaque na passarela; queria um quarto delicado e feminino assim como a Nina [que ainda não nasceu]" (Caras, n.593, mar. 2005). O processo por intermédio do qual o feto é transformado em bebê com qualidades concretas foi denominado por Lo Bianco (1985) de 'psicologização do feto'. Tal processo permite uma reconstrução da maternidade, cujo exercício comporta representações contrastantes entre si.

No caso das celebridades, as referências à identidade feminina ligam-se à manutenção da beleza corporal, aos valores relativos ao trabalho e à constituição da família. A 'vida em família' e a categoria 'casal' exprimem uma experiência muito próxima da vida cotidiana, tanto no universo de camadas médias quanto das populares, caracterizada pela diversidade de práticas e pelas dinâmicas das relações familiares. As práticas reprodutivas e de realização da maternidade fora do casamento (Dauster, dez. 1988), por exemplo, mostram o valor atribuído à necessidade de um pai na reprodução, o que também é revelado pela importância da presença de um homem para apoiar a mulher. A autora analisa a inviabilidade em termos de aliança entre famílias quando a mulher solteira decide ter um filho dissociado 
do casamento. No entanto, a concepção de família, centrada no casal heterossexual com filhos, encontra-se amplamente disseminada em termos culturais e se difundiu como modelo e ideal de comportamento. O modelo do qual se fala é o da família nuclear moderna, formada por 'indivíduos' que ocupam um lugar social definido e normatizado segundo atributos de gênero (Vaitsman, 1994) e onde a vida amorosa e sexual associa-se de forma estreita à função reprodutiva ou à organização conjugal.

As representações de maternidade indicam, por sua vez, conciliações e imagens contrastantes nas representações sobre o trabalho, oriundas da dupla inserção feminina nas esferas pública e privada, como ilustrado nas seguintes referências: "Uma mãe não pode esquecer que ser mulher é o principal. Já estou malhando", diz Kelly Key, 22 anos, cantora (Caras, n.596, abr. 2005). Ou nas palavras de Ingrid Saldanha, 32 anos, atriz e jornalista: "Ser mãe é minha profissão 24 horas por dia" (Caras, n.601, maio 2005). Outra matéria revela que uma apresentadora de TV performática na figura de 'A feiticeira' deixou o trabalho em uma emissora de TV para dedicar-se à casa e ao marido. Nesse caso, vê-se enfatizado o lugar da maternidade e relegado a um segundo plano o trabalho, mesmo diante do destaque e do prestígio conquistados nas telas da televisão brasileira: "Sempre preferi ficar atrás das câmaras. Quero cuidar do David e ter mais dois filhos" (Joana Prado, 28 anos, ex-'feiticeira') (Lombardo, fev. 2005).

$\mathrm{Na}$ encenação visual dos sentidos sobre a maternidade predomina o flagrante da intimidade nas fotos dos famosos: em primeiro plano a casa, o quarto, o banheiro, a família (em geral, os casais com seus filhos, mas também pais e filhos, avós e netos) etc. Nesse cenário, maternidade e gravidez associam-se ao cotidiano familiar dos ídolos, representados de modo fascinante, alçados a essa posição por sua fama, beleza e riqueza. Pretende-se, com esses aspectos da vida dos astros, sugerir a existência de uma vida privada feliz, com amor e conforto, por um lado, e aventura e prazer por outro. Dessa forma expectativas relativas aos laços familiares são geradas a partir da concretude expressa pela chegada do filho. Uma apresentadora famosa anuncia: "Agora a gente vive o filme da vida real. E seremos felizes para sempre" (Angélica, 31 anos, apresentadora de TV) (Salcedo, maio 2005). Cabe ressaltar que a beleza das imagens do casal e de sua criança informa uma experiência bem-sucedida que atrai o espectador, ao mesmo tempo em que exclui todo e qualquer traço dos contratempos vividos pelas mulheres, como os do pós-parto: "Já penso no segundo filho. Engravido daqui a dois anos" afirma Angélica, com o filho de dois meses e meio no colo. São imagens próximas às experiências diárias das mulheres que cogitam ter filhos, mas ao mesmo tempo distantes da realidade e imaginosas. Diz a matéria: "Angélica exerce a maternidade com paixão. Ela mesma dá banho, troca fralda, nina para dormir e garante que vai criar o herdeiro como uma criança normal, 'fora da redoma'". No senso comum não se supõe que os ídolos sejam seres perfeitos, e sim sujeitos a desilusões amorosas, a problemas familiares e fatalidades. No entanto, Caras diferencia-se desse universo das revistas por não revelar as mazelas e o sofrimento de seus astros. Prevalecem imagens extremamente positivas da maternidade, como informa a chamada do artigo sobre Virgínia Nowicki, 40 anos, apresentadora: "Com Gabriel deitado sobre seu corpo, Virgínia agradece esse momento abençoado. Supercuidadosa, ela troca a roupinha do bebê e amamenta. Com um mês e meio e nome de anjo, o bebê é o centro da vida da apresentadora, mesmo 
quando ela trabalha" (Caras, n.587, fev. 2005). A apresentadora destaca os pontos positivos da maternidade, à qual confere um sentido de transformação e de renovação: "Estou loucamente apaixonada por este pequenininho, que chegou na hora certa. A mulher se transforma quando é mãe. Estou recomeçando a vida. Ter um filho é uma benção" (Caras, n.587, fev. 2005). Em outra matéria, a cantora Kelly Key resume o que os filhos representam para ela: "Ser mãe faz com que me sinta uma mulher de verdade, mesmo sendo tão jovem. Devo meu amadurecimento às crianças" (Caras, n.596, abr. 2005). Nessas matérias, fica evidente que as representações em torno do masculino são pouco enfatizadas, embora o nascimento da criança seja retratado pela figura do pai como um evento especial: "Não nasceu só um filho, mas um pai, uma mãe, uma família", diz Hulck, 33 anos, apresentador de TV (Salcedo, maio 2005). Nas razões apontadas para se ter filhos, por exemplo, predominam concepções que tendem à naturalização da reprodução, enquanto característica vinculada ao feminino. Não se observa uma valorização correspondente da paternidade, apesar de os estudos sobre ela indicarem que é concebida como fundamental à construção de um determinado tipo de masculinidade - a dos casados - relacionada à capacidade de sustentar e educar os filhos e não apenas de 'fazê-los' (Costa, 2002). Em meio às mudanças dos costumes, pode-se observar a convocação à participação masculina em certos níveis nas práticas reprodutivas, como se vê na configuração simbólica do 'casal grávido' analisado por Salem (1989).

A reivindicação de paternidade em uniões homossexuais (Uziel, 2007; Tarnovski, 2004; Knibiehler, 2001) denota mudanças no exercício da paternidade uma vez que a expectativa de ser pai tornou-se, em parte, um valor da relação homossexual. Para indivíduos de orientação homossexual a parentalidade esteve circunscrita, até algum tempo atrás, ao relacionamento heterossexual prévio. Estudos sobre o exercício da paternidade e também da maternidade entre solteiros afirmam que pais e mães solteiros (adoção ou reprodução biológica), constituem novos arranjos familiares, apresentando-se como alternativas à constituição do casal, mas como um desejo de constituição de família, ou de um tipo de família (Dauster, dez. 1988). Embora esses arranjos enfatizem o vigor do laço conjugal, a expectativa de paternidade e de maternidade transformou-se. A reprodução nas famílias urbanas, especialmente de camadas médias, é produto do casal individualizado e moderno e não mais uma imposição ou tarefa que diz respeito à família mais ampla.

Nas imagens de Caras, gravidez e maternidade associam-se aos ideais femininos de realização profissional. Algumas tendências demográficas indicam essas transformações nas relações familiares e de gênero, bem como no exercício da sexualidade e das práticas reprodutivas. A importante redução das taxas gerais de fecundidade observada a partir da virada do século XX é consequência, entre outras razões, do maior acesso a recursos contraceptivos e abortivos, e da entrada das mulheres no mercado de trabalho. As mudanças observadas na composição das famílias brasileiras foram profundas e tornaram complexas, por exemplo, as relações entre atividade laboral e família. A análise de Sorj (2004), sobre as políticas e iniciativas que objetivam uma conciliação entre trabalho e vida familiar, aponta conflitos e efeitos negativos na qualidade de vida, especialmente de mulheres e crianças. A participação crescente das mulheres no mercado de trabalho indica que o papel tradicional da mulher tem mudado e sobretudo que as mulheres com crianças incorporam as ocupações mais precárias oferecidas pelo mercado de trabalho. 
Ocorreu uma diminuição na proporção das famílias compostas por casais e parentes do tipo família extensa. Em contrapartida, houve um crescimento significativo das famílias monoparentais femininas, que ocupam o segundo lugar de estrutura familiar mais comum. A maioria das famílias ainda compreende casais com crianças, mas houve um declínio significativo no número de famílias desse tipo. Outras transformações nas relações familiares e de gênero, não menos significativas, podem ser indicadas, como o aumento da proporção de pessoas que vivem sós e um ligeiro crescimento na porcentagem de casais sem crianças (Sorj, 2004). Novos valores associados ao 'viver só' tornam hoje possível a representação da mulher 'solteira' e sem filhos, que também tem sido positivamente incluída como objeto de atenção da mídia. No entanto, ideias preestabelecidas ainda podem ser encontradas, como se verifica na análise de Gonçalves (2007). Para a autora, ainda persistem estereótipos ligados à identidade feminina, no que concerne à percepção da mulher solteira e sem filhos.

O núcleo tradicional composto pelo casal heterossexual com crianças não contitui mais o único modelo de estrutura da família na sociedade brasileira, embora ainda tenha lugar destacado. No entanto, as interferências da parentela nas relações conjugais parecem questionar a ideia de autonomia conjugal, relativizando a autonomização do casal em relação à rede de parentesco, como pode ser observado na pesquisa sobre casais inférteis. A apresentação do desejo por filhos como naturalizado o reduz a uma realização individual, posto que caracterizado por uma experiência sentimental ímpar, íntima e pessoal retratada por Caras, que em nada se assemelha à ideia de racionalização que a noção de 'projeto' no universo de camadas médias encerra (Velho, 1987).

\section{As imagens da 'mulher infértil': os reveses da valorização da reprodução}

Desde as sociedades primitivas, a obsessão da esterilidade (Thébaud, 1991) tem servido de inspiração a ficções jurídicas e às artes e tem incitado os cientistas a descobrir paliativos para a situação. Os debates e as preocupações médicas em torno da esterilidade já estavam presentes no século XIX (Rohden, 2002). A atenção médica nesse período voltava-se para o sexo feminino, instaurando as bases de uma visão moderna da saúde feminina, razão pela qual raras vezes aventaram-se problemas sobre a esterilidade no homem. A noção de infertilidade constituiu-se há muito tempo, sendo vista não apenas como um problema de saúde a ser resolvido pela medicina, mas sobretudo como um problema do âmbito da saúde feminina, visto que a interpretação médica tende a apontar explicações para suas causas na mulher. A infertilidade feminina - e apenas ela - era considerada responsável pela 'infertilidade do casal', não sendo reconhecida, em nossa sociedade, a esterilidade masculina, como em outras sociedades nas quais, por definição, o esperma era fértil (Héritier, 1978).

O significado da inexistência de descendência varia de acordo com a ideologia dominante em cada sociedade, e suas metáforas estão presentes em diferentes contextos históricos e culturais. Em um cenário mais tradicional, a ausência de filhos era vivida como um contrassenso, subvertendo o ciclo das gerações e interrompendo as linhagens as mulheres inférteis assemelhavam-se a um 'corpo entupido', fechado e prisioneiro por 
forças estranhas. Elas foram comparadas a terras estéreis e estiveram associadas a mulas, por sua vez conduzidas por celibatários - também estéreis, mas por vocação (Del Priore, 2001). Em outras culturas as categorias explicativas como frio e quente, seco e úmido são utilizadas para explicar a ausência de descendência, como é o caso dos Samo, de BurkinaFaso (Héritier, 1978) com implicações específicas para os indivíduos em relação à sua posição e desempenho de funções na sociedade. Nas camadas populares no Brasil, a figura da 'figueira do inferno' designa a mulher infértil (Dauster, 1983; Vargas, 1999) e é acionada nas interações locais, familiares e de vizinhança. As representações sociais contemporâneas da infertilidade espelham referências depreciativas - ora acatadas, ora rechaçadas e/ou ressignificadas - às mulheres que 'não podem' ou não 'conseguem' ter filhos biológicos seja nas camadas populares ou médias - e denotam o reverso do valor positivo e socialmente aceito do corpo fértil.

O recurso à adoção de crianças constituiu uma forma de equacionar a infertilidade nos anos 1960 e 1970 (Diniz, 2002) em um período de desenvolvimento rudimentar no que concerne às inovações no campo biomédico, intensificando-se nas camadas médias a partir da década de 1950 (Costa, 1988). A prática de retirar 'pajens' e criadinhas adolescentes dos asilos e orfanatos pelo instrumento denominado 'guarda' não era concebida nos mesmos termos em que é concebida a adoção contemporaneamente. A categoria 'filho adotivo' é recente, construída em um amplo cenário composto pela organização de redes e mediadores, informais e legais, que viabilizam o processo da adoção no Brasil. A prática da adoção firmou-se como uma via efetiva de realização da maternidade e da paternidade por um longo caminho, cheio de transformações, que resultou em um aumento do número de filhos adotivos entre as camadas médias brasileiras. Nos anos 1980, os problemas de infertilidade passam a contar com recursos tecnológicos mais avançados, prevalecendo o uso desses recursos à adoção.

A adoção constitui hoje uma prática presente nos diferentes estratos sociais, embora o apelo de ter o 'próprio filho' por 'via natural' seja bastante expressivo em todos os grupos. As ideias que se apresentam ao senso comum como científicas conferem maior legitimidade à crença que atribui um lugar privilegiado às relações de 'sangue', sobretudo nos estratos letrados, apresentando-se como traço distintivo entre os filhos 'legítimos' e 'adotivos'. Com o objetivo de transpor os muitos obstáculos enfrentados na trajetória do casal é consultada corriqueiramente a internet - sobretudo por mulheres com dificuldades de engravidar (as 'tentantes') -, como recurso a informações sobre tratamentos, o que também contribui para a associação dos problemas relativos ao desejo por filhos com as descrições biomédicas (Vargas, 2006).

Ramirez-Gálvez (2003) considera a divulgação da reprodução assistida na imprensa escrita e na mídia eletrônica um campo recente no Brasil, enquanto o tema das tecnologias reprodutivas é tratado de forma constante na televisão. Telenovelas das décadas de 19902000, como Barriga de aluguel, o seriado Araponga, Laços de família e O clone exemplificam a difusão das informações sobre tecnologias reprodutivas e a institucionalização de novos comportamentos relativos à reprodução. Luna (2003), por sua vez - em investigação da recepção da novela $O$ clone entre pacientes em tratamento ambulatorial -, analisou de que modo os novos procedimentos da biotecnologia afetam as noções de parentesco no Brasil. 
Eliane Portes Vargas

$\mathrm{Na}$ pesquisa sobre casais inférteis (Vargas, 2006) foram observadas imagens depreciativas da 'mulher infértil' em cenas das novelas Senhora do destino e América (ambas produzidas em 2005), as denominadas 'novelas das oito' da televisão brasileira que, em termos de recepção e audiência (Leal, 1985), alcançam parcela significativa da população. A primeira, da Rede Globo, incluiu em seu repertório uma personagem estéril, cuja representação repercutiu de forma negativa na mídia. Fragmentos dessa novela foram divulgados pela jornalista Cláudia Collucci (28 jan. 2005) sob o título "A visão deturpada da esterilidade". Em outra matéria, intitulada "Senhora do destino", a jornalista informa os termos usados na trama da Rede Globo, considerados 'pejorativos' e 'cruéis' (Collucci, 16 fev. 2005). Segundo a reportagem, os termos pejorativos 'seca' e 'oca', direcionados à personagem estéril e vilã, são empregados muitas vezes e constituem as razões da crítica contundente por parte também de grupos da sociedade civil preocupados com o tema.

A representação do desejo por filhos como 'obsessão', por parte das mulheres - mas não como preocupação dos homens -, portanto, não é nova, mas adquire outros contornos. Os meios de comunicação afirmam o valor positivo da reprodução e exploram as circunstâncias sociais que envolvem o atual desejo por filhos, tais como tê-los por opção, o adiamento da maternidade em função das perspectivas profissionais - a chamada maternidade 'tardia' etc. O assunto é amplamente explorado, sendo relacionado às mudanças de atitudes na sociedade contemporânea. Como se pode ver, o desejo de reprodução e de ter filhos - construído como um fato biológico a partir de uma determinada configuração simbólica - é retratado de modo convergente aos valores sociais predominantes em nossa época, ainda que as representações excluam toda sorte de tensões e conflitos inerentes às relações sociais que as constituem.

\section{Considerações finais}

Neste trabalho tematizei, em um cenário de transformação dos valores e das práticas reprodutivas, como os meios de comunicação afirmam a valorização da maternidade através da ênfase dada às imagens do corpo grávido. Essa dimensão positiva do corpo e da reprodução, expressa pela gravidez, convive com a difusão das descrições biomédicas acerca da infertilidade conjugal e com metáforas não eruditas sobre infertilidade, apresentada como um revés da identidade feminina. A valorização da reprodução da família, do nome, do grupo e da pessoa é uma característica presente em todas as culturas. Mas na sociedade moderna, não reproduzir, por um impedimento biológico, aciona uma peculiar combinação de valores que expõe os limites da liberdade de escolha do casal.

No âmbito da conjugalidade heterossexual o valor atribuído à reprodução torna-se mais evidente visto por seu revés, ou seja, a 'não reprodução involuntária', caracterizada como um impedimento biológico que contraria a decisão racional de ter filhos, ligada à ideia de 'projeto' e de 'realização a dois'. Essa experiência, denominada 'infertilidade conjugal' pela biomedicina, reflete-se de modo significativo na dinâmica conjugal. $\mathrm{O}$ anseio dos casais por conceber um filho de modo natural resulta no agenciamento de um extenso aparato tecnológico para produzir uma gravidez 'natural'. Essa, por sua vez, sobrepõe-se à ideia de escolha, autonomia e espontaneidade como dimensões relevantes da constituição 
do par e da vida a dois. A dimensão da 'escolha', como valor cultural relevante parece, portanto, tornar possível a acomodação das ingerências na dinâmica conjugal advindas das orientações e prescrições médicas diferenciadas para homens e mulheres.

Por fim, poderíamos ainda pensar o quanto esse valor positivo da reprodução encontrase delimitado por posições não só de gênero, mas também de geração, classe e orientação sexual. Tomando por base a literatura disponível e o debate em torno do tema (Heilborn, 2004), considero que existe um raciocínio reducionista na percepção dos eventos reprodutivos divulgados na mídia, pois não se observa um valor semelhante quando se trata de outros fenômenos sociais, sobretudo aqueles considerados problemas sociais. O aumento de gravidez na adolescência, por exemplo, clama por solução em função de sua ocorrência nas camadas populares, sendo comumente questionada a autonomia dos jovens relacionada ao desejo de reproduzir; os altos índices de óbito materno entre as mulheres pobres, outro evento relacionado ao nascimento e ao parto, são considerados evitáveis devido aos recursos médicos disponíveis. No entanto, essa problemática não tem merecido o devido destaque, sendo tal evento negligenciado. Nesse grupo da população economicamente desfavorecida a infertilidade, por sua vez, não é problematizada em termos de debate público uma vez que não é considerado tema de relevância para mulheres pobres. Soma-se a esses aspectos, ligados ao gênero e à classe, o impedimento de acesso às técnicas de reprodução assistida a homossexuais; as recomendações normatizadoras do Conselho Federal de Medicina no 1957/ 2010 apenas recentemente modificaram (ao menos em potencial) esse quadro, o que permitirá o avanço do debate nessa direção. Não havendo lei regulatória sobre o tema, a resolução anterior no 1358/1992, revogada pela atual, indicava que apenas as mulheres podiam ter acesso aos procedimentos de reprodução assistida e, caso fossem casadas ou vivessem em união com seus companheiros, precisavam do consentimento deles.

Tendo em vista o papel relevante dos modernos meios de comunicação - como indicado pela literatura -, tais como o cinema, a mídia televisiva e, mais recentemente, a chamada comunicação 'virtual' na sociedade contemporânea, chamo atenção para os valores associados à gravidez inscrita no corpo feminino nesses meios e para seus usos. Nas práticas decorrentes dos usos das tecnologias reprodutivas analisadas por Luna (2002, p.278) a gravidez desponta como "símbolo de uma maternidade sacralizada". Assim também ocorre na ampla exposição midiática do corpo grávido, em que é ignorado o fato de tratar-se de evento relacionado a uma construção social.

\section{NOTAS}

${ }^{1}$ Este artigo incorpora as reflexões da comunicação "Desejo de filhos e ideal de maternidade: um estudo da maternidade e da gravidez na mídia" (Vargas; Russo, 2005), apresentada na Sexta Reunião de Antropologia do Mercosul, Montevidéu, em novembro de 2005. Trata-se de alguns resultados da minha pesquisa de doutorado, Casais inférteis: usos e valores do desejo de filhos entre casais de camadas médias no Rio de Janeiro (Vargas, 2006), sob orientação de Jane Russo e coorientação de Maria Luiza Heilborn. Agradeço a ambas a contribuição na proposição do tema e a fecunda reflexão sobre corpo e gênero no decorrer da pesquisa mais ampla.

${ }^{2}$ São 16 entrevistados unidos (união civil ou estável); inseridos no mercado de trabalho (ao menos um dos cônjuges); universitários (ao menos um dos cônjuges); com ou sem filhos; residentes em bairros das Zonas Norte e Sul do Rio de Janeiro e com condições sociais e materiais semelhantes de acesso ao consumo de bens e de tecnologias médicas. 


\section{REFERÊNCIAS}

BELMIRO, Celia Abicalil.

A fotografia na construção visual da gravidez.

Dissertação (Mestrado) - Escola de

Comunicação, Universidade Federal do Rio de Janeiro, Rio de Janeiro. 1992.

BERQUÓ, Elza S.; CAVENAGHI, Suzana. Mapeamento sócio-econômico e demográfico dos regimes de fecundidade no Brasil e sua variação entre 1991 e 2000. In: Encontro Nacional de Estudos Populacionais, 14., 20-24 set. 2004, Caxambu. Anais... Caxambu:

Associação Brasileira de Estudos Populacionais. p.1-18. 2004.

BORIN, Françoise.

Uma pausa para a imagem. In: Duby, Georges; Perrot, Michelle (Org.). História das mulheres no Ocidente: do Renascimento à Idade Moderna. Porto: Afrontamento; São Paulo: Ebradil. p.253-294. 1991.

BOZON, Michel.

Sociologia da sexualidade. Rio de Janeiro: Editora FGV. 2004.

CHAZAN, Lílian Krakowski.

"É... tá grávida mesmo! E ele é lindo!": a construção de 'verdades' na ultra-sonografia obstétrica. História, Ciências, Saúde Manguinhos, Rio de Janeiro, v.15, n.1, p.99-116. 2008.

CITELI, Maria Tereza.

A reprodução humana na pauta dos jornais brasileiros, 1996-2000. In: Comissão de cidadania e reprodução. Olhar sobre a mídia. Belo Horizonte: Mazza. p.184-212. 2002.

COLLUCCI, Cláudia.

Senhora do destino. Folha de São Paulo, São

Paulo. Disponível em: http://

www1.folha.uol.com.br/fsp/cotidian/

ff1602200512.htm. Acesso em: 18 fev. 2012.

16 fev. 2005

COLLUCCI, Cláudia.

A visão deturpada da esterilidade. Folha de São Paulo, São Paulo. Disponível em: http:// www1.folha.uol.com.br/folha/colunas/ querosermae/ult601u213.shtml. Acesso em 8 fev. 2012. 28 jan. 2005.

COlTRUGliO, Carina.

Virginia Nowicki, mãe: ela apresenta Gabriel, seu primeiro filho. Caras, São Paulo, n.587, fev. 2005.

COSTA, Maria Cecília Solheid.

Os 'filhos do coração': adoção em camadas médias. Tese (Doutorado) - Museu Nacional, Universidade Federal do Rio de Janeiro, Rio de Janeiro. 1988.
COSTA, Roseli Gomes.

Reprodução e gênero: paternidades,

masculinidades e teoria da concepção. Estudos Feministas, Florianópolis, v.10, n.2, p.339-356. 2002.

DAUSTER, Tania.

A experiência 'obrigatória': uma interpretação sobre a maternidade fora do casamento em camadas médias urbanas. Boletim do Museu Nacional, Rio de Janeiro, n.59, dez. 1988.

DAUSTER, Tania.

O lugar da mãe. Comunicações ISER, Rio de Janeiro, ano 2, n.7, p.16-20. 1983.

\section{DEL PRIORE, Mary.}

Homens e mulheres: o imaginário sobre a esterilidade na América portuguesa. História Ciências, Saúde - Manguinhos, v.8, n.1, p.99-112. 2001.

DINIZ, Débora.

Introdução. In: Diniz, Débora; Buglione, Samantha (Org.) Quem pode ter acesso às tecnologias reprodutivas?: diferentes perspectivas do direito brasileiro. Brasília: Letras Livres. p.9-21. 2002.

EDITORA ABRIL.

Relatório sobre as demonstrações contábeis em 31 de dezembro de 2000 e 1999 (Legislação Societária). Disponível em: http:// www.abril.com.br/aempresa/balanco/ rel_admin_00.pdf. Acesso em: 5 jul. 2009. 2001.

FRANÇA, Vera Regina Veiga.

Sociabilidade: implicações do conceito de comunicação. In: Braga, J. L.; Porto, S. D.; Neto, A. F. A encenação dos sentidos: mídia, cultura e política. Rio de Janeiro: Associação Nacional dos Programas de Pós-graduação em Comunicação/Diadorim. p.55-66. 1995.

FREIRE, Maria Martha de Luna.

'Ser mãe é uma ciência': mulheres, médicos e a construção da maternidade científica na década de 1920. História, Ciências, Saúde Manguinhos, Rio de Janeiro, v.15, supl., p.153-171. 2008.

\section{GONÇALVES, Eliane.}

Vidas no singular: noções sobre "mulheres sós" no Brasil. Tese (Doutorado) - Instituto de Filosofia e Ciências Humanas, Universidade Estadual de Campinas, Campinas. 2007.

HEILBORN, Maria Luiza.

Dois é par: gênero e identidade sexual em contexto igualitário. Rio de Janeiro: Garamond. 2004.

HEILBORN, Maria Luiza.

Uma rota perigosa. O Globo, Rio de Janeiro. p.7. 7 out. 2004. 
HÉRITIER, Françoise.

Fécondité et stérilité: la traduction de ces notions dans le champ idéologique au stade préscientifique. In: Sullerot, Evelyne. Le fait féminin. Paris: Fayard, p.387-396.1978.

HOLLENBACH, Gabriela Boemler. O casamento e a TPM: novos tempos, novos sentidos. Em Questão, Porto Alegre, v.9, n.2, p.255-269. 2003

KNIBIEHLER, Yvonne.

Introduction: la construction sociale de la maternité. In: Knibiehler, Yvonne (Ed.).

Maternité: affaire privée, affaire publique. Paris: Bayard. p.13-20. 2001

LEAL, Ondina Fachel.

A leitura social da novela das oito. Petrópolis: Vozes. 1985

LEITE, Miriam Moreira.

Retratos de família: leitura da fotografia histórica. São Paulo: EdUnesp. 2000.

LO BIANCO, Anna Carolina.

A psicologização do feto In: Figueira, Sérvulo (Org.). Cultura da psicanálise. São Paulo: Brasiliense. p.94-115. 1985.

LOIS, George.

Flashback: Demi Moore. Vanity Fair, New York. Disponível em:

http://www.vanityfair.com/hollywood/ features/2011/08/demi-moore-201108. Acesso em: 8 fev. 2012. Aug. 1991.

LOMBARDO, Elenice Brígida.

Joana Prado e seu Davi: ex-feiticeira sai da TV e vai viver para a família. Caras, São Paulo, n.606, fev. 2005.

LUNA, Naara.

A personalização do embrião humano: da transcendência na biologia. Mana, Rio de Janeiro, v.13, n.2, p.411- 440. 2007.

LUNA, Naara.

Novela e biotecnologia: os pais de 'O clone' segundo mulheres em tratamento de fertilidade. In: Pillar, M.; Porto, R. e Tamanini, M. (Org.). Novas tecnologias reprodutivas conceptivas: questões e desafios. Brasília: Letras Livres. p.53-66. 2003.

LUNA, Naara.

Maternidade desnaturada: uma análise da barriga de aluguel e da doação de óvulos. Cadernos Pagu, Campinas, n.19, p.233-278. 2002.

MACHADO, Marcia; HAGEN, Sean.

A glamourosa vida de uma estrela do jornalismo: como as revistas femininas representam a diva Fátima Bernardes. Em Questão, Porto Alegre, v.10, n.1, p.63-79. 2004.
MALUF, Sônia Weidner.

Corpo e corporalidade nas culturas contemporâneas: abordagens antropológicas. Esboços, Florianópolis. n.9, p.87-101. 2002.

MARTINS, Ana Paula Vosne.

"Vamos criar seu filho": os médicos puericultores e a pedagogia materna no século XX. História, Ciências, Saúde - Manguinhos, Rio de Janeiro, v.15, n.1, p.135-154. 2008.

MAUSS, Marcel.

As técnicas corporais. In: Mauss, Marcel. Antropologia e sociologia. São Paulo: Editora Pedagógica e Universitária; EdUSP. v.2. p.209233. 1974.

MENEZES, Raquel Aisengart.

Tecnologia e 'morte natural': o morrer na contemporaneidade. Physis, Rio de Janeiro, v.13, n. 2, p.367-385. 2003.

MIRA, Maria Celeste.

O leitor e a banca de revistas: a segmentação da cultura no século XX. São Paulo: Olho d'Água; Fapesp. 2001.

NOVAES, Simone; SALEM, Tania.

Recontextualizando o embrião. Estudos

Feministas, Florianópolis, v.3, n.1, p.65-88.

1995.

PEIXOTO, Clarice Ehlers; DE SINGLY, Françoise; CICCHELLI, Vicenzo.

Família e individualização. Rio de Janeiro: Editora FGV. 2000.

PERROT, Michelle; DUBY, Georges.

História das mulheres no Ocidente: do Renascimento à Idade Moderna. Porto: Afrontamento; São Paulo: Ebradil. v.3. 1991.

RAMIREZ-GÁLVEZ, Martha Celia.

Novas tecnologias reprodutivas conceptivas:

fabricando a vida, fabricando o futuro. Tese (Doutorado) - Instituto de Filosofia e Ciências Humanas, Universidade Estadual de Campinas, Campinas. 2003.

REVISTA CARAS

Caras: mídia kit. Pesquisa segmentada. Disponível em: http://caras.uol.com.br/ anuncie/revista/pesquisa.html. Acesso em: 7 jul. 2009. 2008.

REZENDE, Cláudia.

Um estado emotivo: representação da gravidez na mídia. Cadernos Pagu, Campinas, n.36, p.315-344. jan.-jun. 2011.

RIBEIRO, Cláudia Regina; ROHDEN, Fabíola. A ciência na mídia e as estratégias de reafirmação da bipolaridade entre os gêneros: o caso do Globo Repórter. Cadernos Pagu, Campinas, n.32, p.267-299. 2009.

ROHDEN, Fabíola.

Ginecologia, gênero e sexualidade na ciência 
do século XIX. Horizontes Antropológicos, Porto Alegre, ano 8, n.17. p.101-125. 2002.

ROJAS, Carlos Antonio Aguirre.

1968 as a turning point in historical thinking: changes in western historiography. História, Franca, v.23, n.1-2, p.197-218. 2004.

RUSSO, Jane Araújo; PONCIANO, Edna. L. T. O sujeito da neurociência: da naturalização do homem ao re-encantamento da natureza. Physis, Rio de janeiro, v.12, n.2, p.345-367. 2002.

SALCEDO, Aline.

Angélica e Huck e a rotina com Joaquim: orgulhosos do primeiro filho o casal posa para exclusivo ensaio em família. Caras, São Paulo, n.603, maio 2005.

SALEM, Tania.

As novas tecnologias reprodutivas: o estatuto do embrião e a noção de pessoa. Mana, Rio de Janeiro, v.3, n.1, p.75-94. 1997.

SALEM, Tania.

O individualismo libertário no imaginário social dos anos 60. Physis, Rio de Janeiro, v.1, n.2, p.58-75. 1991.

SALEM, Tania.

O casal igualitário: princípios e impasses.

Revista Brasileira de Ciências Sociais, São Paulo, v.9, n.3, p.24-37. 1989.

SANZIO, Raffaelle.

La donna gravida. Disponível em: http:// www.wga.hu/html_m/r/raphael/2firenze/1/

27 gravid.html. Acesso em: 10 set. 2005 . 1505-1506.

SHARI, L. Dworkin; FAYE, Linda Wachs. 'Getting your body back': postindustrial fit motherhood in shape fit pregnancy magazine. Gender \& Society, Newbury Park, Ca., v.18, n.5, p.610-624. 2004.

SIMILI, Ivana Guilherme.

Educação e produção de moda na Segunda Guerra Mundial: as voluntárias da Legião Brasileira de Assistência. Cadernos Pagu, Campinas, n.31, p.439-469. 2008.

SORJ, Bila.

Reconcilling work and family: issues and policies in Brazil. Geneva: Internacional Labour Organization. 2004.

SORJ, Bila; GOLDEMBERG, Miriam.

Um novo modelo de família: coesão e centramento nos filhos. Interseções, Rio de Janeiro, ano 3, n.2, p.113-119. 1999.

SWAIN, Tania Navarro.

Feminismo e recortes do tempo presente: mulheres em revistas 'femininas'. São Paulo em Perspectiva, São Paulo, v.15, n.3, p.67-81. 2001.
TAMANINI, Marlene.

Reprodução assistida e gênero: o olhar das ciências humanas. Florianópolis: EdUFSC. 2009.

TARNOVSKI, Flávio Luiz.

"Pai é tudo igual?": significados da paternidade para homens que se autodefinem como homossexuais. In: Piscitelli, A.; Gregori, M.F., Carrara, Sérgio (Org.). Sexualidade e saberes: convenções e fronteiras. Rio de Janeiro: Garamond. p.385-414. 2004.

THÉBAUD, Françoise.

O século XX. In: Duby, G.; Perrot, M. (Org.). História das mulheres no Ocidente. Porto: Afrontamento; São Paulo: Ebradil. p.637657.1991.

TORNQUIST, Carmen Suzana.

Armadilhas da nova era: natureza e maternidade no ideário da humanização do parto. Estudos Feministas. Florianópolis, v.10, n.2, p.483-492. 2002.

UZIEL, Anna Paula.

Homossexualidade e adoção. Rio de Janeiro:

Garamond. 2007.

VAITSMAN, Jeni.

Hierarquia de gênero e iniqüidade em saúde. Physis, Rio de Janeiro, v.4, n.1, p.7-22. 1994.

VARGAS, Eliane Portes.

'Casais inférteis': usos e valores do desejo de filhos entre casais de camadas médias no Rio de Janeiro. Tese (Doutorado) - Instituto de Medicina Social, Universidade Estadual do Rio de Janeiro, Rio de Janeiro. 2006.

VARGAS, Eliane Portes.

A figueira do inferno: os reveses da identidade feminina. Estudos Feministas, Rio de Janeiro, v.7, n.1-2, p.89-108. 1999.

VARGAS, Eliane Portes; RUSSO, Jane. Desejo de filhos e ideal de maternidade: um estudo da maternidade e da gravidez na mídia. In: Reunião de Antropologia do Mercosul, 6., 16-18 nov. 2005, Montevidéu. Anais...

Montevidéu: Universidad de la República. CD-Rom. 2005.

VARGAS, Eliane Portes; RUSSO, Jane; HEILBORN, Maria Luiza.

Sexualidade e reprodução: usos e valores relativos ao desejo de filhos entre casais de camadas médias no Rio de Janeiro. Cadernos de Saúde Pública, Rio de Janeiro, v.26, n.1, p.153-162. 2010.

VELHO, Gilberto.

Individualismo e cultura: notas para uma antropologia da sociedade contemporânea. Rio de Janeiro: Zahar. 1987. 